\title{
Certain considerations in the alignment design of urban railways
}

\author{
B. Kufver ${ }^{1} \&$ G. Hallert ${ }^{2}$ \\ ${ }^{1}$ Ferroplan, Sweden \\ ${ }^{2}$ WSP International, Sweden
}

\begin{abstract}
Railway alignment has a high degree of permanence and should be seen in a context of at least 100 years. Installations such as track superstructure, catenary system, etc., are less permanent since these subsystems are commonly renewed without alteration of the alignment. When new lines are built, there are relatively few obstacles along the route, and the available terrain corridor allows a relatively large number of possible alignment alternatives. There are only a few international standards for alignment design of railways (including urban railways), and they should be recognised as standards presenting limits and not as design handbooks or design manuals giving recommendations or normal design values. The present paper discusses the application of European standards in an overseas project (a new commuter railway), and the need for further design criteria where margins to the limits in the standard can be achieved at no or low cost. Such design criteria should focus on provisions for changed operational requirements, such as future turnouts, introduction of skip-stop trains and a general increase in permissible speeds. Furthermore, certain risks with modern slab tracks instead of traditional ballasted tracks are discussed.

Keywords: alignment design, European standards, ENV 13803-1, EN 13803-1.
\end{abstract}

\section{Introduction}

The present conference paper describes and discusses the application of European standards for track alignment in a project where an urban railway for commuter traffic (maximum permissible speed $160 \mathrm{~km} / \mathrm{h}$, inter-station distances from $1 \mathrm{~km}$ up to $14 \mathrm{~km}$ ) was designed in a country which did not have any national standards for railways. In this particular project, the contractor's 
consultants come from one country, while the client's organisation was manned with engineers from other countries, with other views on good practice and priorities between objectives in conflict.

\section{Alignment standards}

There are few international standards for track alignment. UIC has published a leaflet [1] with rules for certain Line Categories, such as

a. I. Mixed traffic lines with a permissible speed $80-120 \mathrm{~km} / \mathrm{h}$ for passenger trains.

b. II. Mixed traffic lines with a permissible speed $120-200 \mathrm{~km} / \mathrm{h}$ for passenger trains.

c. III. Mixed traffic lines with a permissible speed $\leq 250 \mathrm{~km} / \mathrm{h}$ for passenger trains, new lines for FS.

d. III. Mixed traffic lines with a permissible speed of $\leq 250 \mathrm{~km} / \mathrm{h}$ for passenger trains, new lines for DB.

e. IV. Dedicated passenger lines for a permissible speed of $250-300 \mathrm{~km} / \mathrm{h}$.

The European Committee for standardisation (CEN) published in 2002, a European prestandard for plain track [2] and in 2006, a European standard for switches and crossings [3]. The prestandard for plain track alignments [2] contains so called "Traffic Categories", similar to the Line Categories in [1]:

f. I. Mixed traffic lines with a permissible speed of $80 \leq V \leq 120 \mathrm{~km} / \mathrm{h}$.

g. IIa. Mixed traffic lines with a permissible speed of $120<V<160 \mathrm{~km} / \mathrm{h}$.

h. IIb. Mixed traffic lines with a permissible speed of $160<V \leq 200 \mathrm{~km} / \mathrm{h}$.

i. III. Mixed traffic lines with a permissible speed of $200<V \leq 300 \mathrm{~km} / \mathrm{h}$ for passenger trains.

j. IV. Mixed traffic lines with a permissible speed of $V \leq 250 \mathrm{~km} / \mathrm{h}$ for passenger trains (with vehicles incorporating special design characteristics).

k. V. High-speed lines with dedicated passenger traffic, $250<V \leq 300 \mathrm{~km} / \mathrm{h}$.

There are many similarities between the Line Categories in UIC 703 [1] and the Traffic Categories in ENV 13803-1 [2]. None of the documents refers to dedicated passenger lines for a lower permissible speed than $250 \mathrm{~km} / \mathrm{h}$, or dedicated freight lines.

The concept of Line Categories for vehicles with special technical design characteristics may suit railway companies which comprise both infrastructure, rolling stock and operations. However, with separation between infrastructure and operations, the concept does not hold. Since line Category IV in [2] represents a mixed traffic line with both passenger trains with especially low axle load and freight trains (with comparatively high axle load), there are no technical reasons why such track should not be able to carry a normal passenger train. Refusal of track access for a normal passenger train, with axle loads below those of a freight train, would contradict all ambitions of interoperability. The question that arises is just at what speed (or cant deficiency) a normal passenger train may run on the Category IV line [4]. (Hence, the Traffic Categories have 
been deleted in an updated version of the CEN standard for plain track alignments [5].)

In this particular project for an urban commuter railway, a dedicated passenger line with a maximum permissible speed up to $160 \mathrm{~km} / \mathrm{h}$, it was decided to use the European standards for the alignment.

However, it was also recognized that the European standards [2], [3] and [5] are not design handbooks or design manuals, stating normal design values, but standards defining the requirements as inequalities, such as eqns. (1)-(4). Such inequalities leave considerable room for an optimisation of the track alignment.

$$
\begin{gathered}
V_{\text {train }} \leq V_{\text {perm }} \\
V_{\text {perm }} \leq V_{\text {track }} \\
X\left(V_{\text {track }}\right) \leq X_{\text {lim }} \\
Y\left(V_{\text {track }}\right) \geq Y_{\text {lim }}
\end{gathered}
$$

where $V_{\text {train }}$ is the actual train speed in operation, $V_{\text {perm }}$ is permissible speed as applied in the signalling system, $V_{\text {track }}$ is the permissible speed when the rules in the track alignment standards are applied, $X$ is a track design variable (for example cant, cant deficiency, gradient) with a upper limit $\left(X_{\text {lim }}\right)$, and $Y$ is a track design variable (for example horizontal radius) with a lower limit $\left(Y_{\text {lim }}\right)$.

The exceptional limits in the European standards are chosen from an umbrella approach aimed to allow all values already used on (at least some of the) European railways. Also the normal limits are sometimes less conservative than the limits applied by certain European railways. Hence, the CEN standards on alignments specifically state that further requirements may be found in national or company standards.

\section{Performance indicators and object functions}

There are many possible performance indicators for railway infrastructure, such as permissible speed $\left(V_{\text {track }}\right)$, comfort, permissible axle load, train interval, maintenance needs and provisions for adaptations to future changes in configurations, etc.

The alignment affects permissible speed, comfort, forces between wheels and rails, maintainability of the track and whether or not the railway infrastructure contains provisions for future changes. (The risk of derailments is already eliminated by the level of the limits, eqns. (3) and (4), but extra margins can be justified to derailment related limits.)

These performance variables are sometimes, but not always, in conflict. In Sweden, permissible speed is normally used as the object function in the alignment design, for examples see $[6,7]$. (Other countries use horizontal radius as object function, or do not specify any object function at all.) If permissible speed is higher than the actual operational speed, the forces on the track will be lower and passenger comfort better. By definition, there will also be a provision for higher operational speeds and changed operational pattern (such as skip-stop trains etc). Provisions for additional platforms and additional turnouts are likely 
to be in conflict with permissible speed and can in the design process be considered as boundary conditions. Since cant can be changed more easily after the railway has been built, it may have a lower value if that better suits the actual train speed in operation $\left(V_{\text {train }}\right)[8]$.

\section{Design considerations}

\subsection{Alignment corridor}

The first requirement in an alignment design is that the available terrain corridor has been defined. Otherwise, the best solution would be to design and build an entirely straight railway.

The border of the terrain corridor should be defined from a perspective of construction costs (general costs, including value of land-take or physical constraints of importance). If the border can be exceeded without additional costs, it has not been correctly defined.

A project may study several terrain corridors, each associated with its own construction cost and its own performance.

\subsection{Straight tracks}

The straight tracks are normally the preferred alignment elements. They are easier to maintain with tamping machines than curves (since the machines can easily be guided by laser beams).

Straight tracks are also more suitable for turnouts (or provisions for future turnouts).

Straight tracks along a platform minimise the gap between the train and the platform.

\subsection{Horizontal radius}

Where horizontal curves are inserted, it is normally recommended that a large radius is used.

However, very large radii have some disadvantages. Certain software for alignment design and geodetic survey data may not be able to handle radii above 99999.999 metres. Another aspect is that a large radius leads to shorter connecting straight lines.

In this particular project the client's organisation opposed the use of $3 \mathrm{~km}$ long curves with a horizontal radius of 9000 metres, and recommended that the radius was reduced to $3000 \mathrm{~m}$ which would still, with considerable margin, allow the permissible speed as applied in the signalling system $\left(V_{\text {perm }}=160 \mathrm{~km} / \mathrm{h}\right)$. Hence, the connecting straights became longer.

Very large radii may be justified for very short curves, where the change of direction is very small, but in other cases long adjacent straight tracks should be prioritised. 


\subsection{Applied cant}

Where transition curves are sufficiently long, the applied cant will be limited upwards with an upper limit for cant and downwards with an upper limit for cant deficiency (for $V_{\text {perm }}$ ). In most curves this leads to a permissible interval for applied cant, so further criteria may be introduced.

In order to maintain good comfort according to the European Standard for comfort evaluation, EN 12299 [9], the cant deficiency should be lower than about $50 \mathrm{~mm}$. In order to provide an option for raised permissible speed $\left(V_{\text {perm }}\right)$, the cant deficiency needs to have a margin with respect to the limit for cant deficiency. The two aspects are normally not in conflict.

For curves near an adjacent speed restriction and/or curves near a platform, the actual train speed in operation $\left(V_{\text {train }}\right)$ is normally lower than the permissible speed $\left(V_{\text {perm }}\right)$, due to limitations in the acceleration and deceleration capabilities of the train. In such cases the applied cant should be lower than "normal" (where trains are running at constant speed), and cant deficiency would be higher than "normal". Such curves may require longer transition curves, see Section 4.6. These considerations are in conflict with an approach where applied cant, for a given permissible speed $\left(V_{\text {perm }}\right)$, is strictly proportional to curvature (the inverse of the radius). Hence, the client's representatives required all cant values to be calculated individually for each curve, and not with a constant proportion to curvature.

An example from the actual project demonstrates this effect. Close to a terminus station, a horizontal curve has a radius of 550 metres. It is followed by a short straight (64 metres long) and then a curve with 1300 metres radius. The first curve allows $80 \mathrm{~km} / \mathrm{h}$ at $60-77 \mathrm{~mm}$ cant (the cant is low due to short transition curves). The contractor's consultant suggested $70 \mathrm{~mm}$ of applied cant and $67 \mathrm{~mm}$ of cant deficiency, which was accepted by the client. The second curve allows $120 \mathrm{~km} / \mathrm{h}$ at $58-73 \mathrm{~mm}$ cant. The contractor's consultant suggested $66 \mathrm{~mm}$ of applied cant and $65 \mathrm{~mm}$ of cant deficiency (for the design speed $120 \mathrm{~km} / \mathrm{h}$ ). This was not accepted by the client, since due to the short straight, a train length of 200 metres and limitation in possible (longitudinal) acceleration, the front of the train would enter the second curve at $80 \mathrm{~km} / \mathrm{h}$ (or less) and with cant excess. Hence, for this particular curve, the applied cant should be lower than "normal". This would require longer transition curves (see Section 4.6), and therefore must be taken into account already when the horizontal alignment is designed.

\subsection{Skip-stop trains}

In the specification of this particular project, it was stated that fast skip-stop trains may be introduced at a later stage. Such trains may justify a higher permissible speed $\left(V_{\text {perm }}\right)$ than otherwise considered, especially through stations, and should be taken into consideration in the alignment design also at early design stages and to avoid subsequent design restrictions. 


\subsection{Transition curves}

In railway applications, the most common type of transition curve is the clothoid, where curvature and cant vary linearly with chainage. Clothoids are also used in the actual project. It was not considered interesting to use doucines, Bloss curves or other types of s-shaped ramps and corresponding types of transition curve.

The lower limit for length of a transition curve $\left(L_{t}\right)$ is determined from limits for the cant gradient, the rate of change of cant and the rate of change of cant deficiency, eqns. (5)-(7) $[1,2,5]$.

$$
\begin{gathered}
L_{t} \geq \frac{\Delta D}{(d D / d s)_{\lim }} \\
L_{t} \geq \frac{\Delta D}{(d D / d t)_{\lim }} \cdot \frac{V_{\text {track }}}{3.6} \\
L_{t} \geq \frac{\Delta I}{(d I / d t)_{\lim }} \cdot \frac{V_{\text {track }}}{3.6}
\end{gathered}
$$

where $L_{t}$ is the length of the transition curve $(\mathrm{m}), \Delta D$ and $\Delta I$ are the change of cant and cant deficiency respectively $(\mathrm{mm}),(d D / d s)_{\text {lim }}$ is the upper limit for cant gradient $(\mathrm{mm} / \mathrm{m}),(d D / d t)_{\text {lim }}$ and $(d I / d t)_{\text {lim }}$ are the upper limit for rate of change of cant and the upper limit for rate of change of cant deficiency respectively $(\mathrm{mm} / \mathrm{s})$ and $V_{\text {track }}$ is the permissible speed with respect to track alignment criteria $(\mathrm{km} / \mathrm{h})$.

The example in Section 4.4, the horizontal curve with 1300 metres radius, demonstrates the consequences of the fact that not only the limits but also permissible speed, the applied cant and the cant deficiency define the lower limit for the length of a transition curve. The curve should be designed to allow a train speed of $120 \mathrm{~km} / \mathrm{h}$, but the applied cant should also be suitable for the front of the train which will enter the curve at a speed of $80 \mathrm{~km} / \mathrm{h}$. This justifies an applied cant lower than normal. Hence, cant deficiency at the permissible speed of $120 \mathrm{~km} / \mathrm{h}$ will be higher than normal, and also the lower limit for transition length according to eqn. (7) will be higher. Hence, longer transition curves increase the operational flexibility and optimise the design.

The consideration of skip-stop trains (Section 4.5) may also justify longer transition curves. A commonly used radius in this project is 2000 metres. At a train speed of $160 \mathrm{~km} / \mathrm{h}$, the equilibrium cant becomes $151 \mathrm{~mm}$. The contractor's consultant proposed $77 \mathrm{~mm}$ applied cant, $74 \mathrm{~mm}$ cant deficiency and 68 metres long transition curves. The rate of change of cant would be $50 \mathrm{~mm} / \mathrm{s}$ (no margin to the limit in [2] and [5]), and the rate of change of cant would be $49 \mathrm{~mm} / \mathrm{s}$ while the limit in [2] and [5] is $55 \mathrm{~mm} / \mathrm{s}$. This leaves no opportunities to increase the permissible speed above $160 \mathrm{~km} / \mathrm{h}$ for skip-stop trains. The short transition curves also prevent reduction of the cant deficiency to more comfortable values (according to the definitions of ride comfort in [9]). Figure 1 shows the design values for the first $19.4 \mathrm{~km}$ of the project. Rate of change of cant deficiency is increased speed, even though there are margins with respect to cant deficiency (and horizontal radius). 


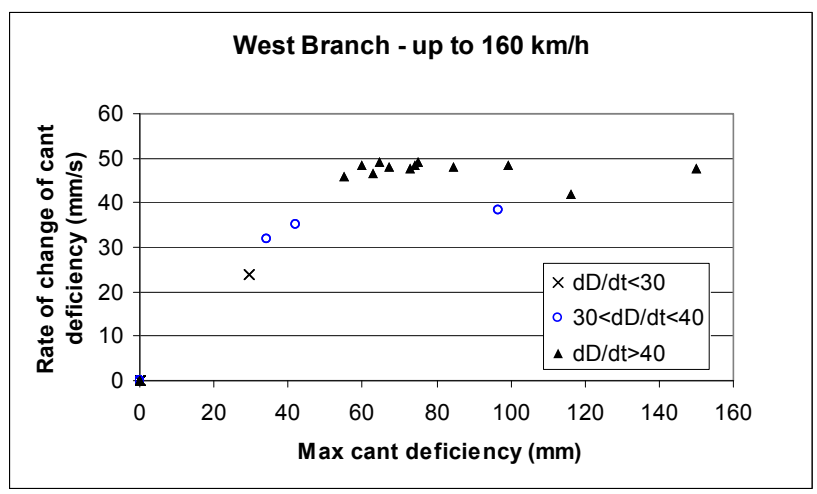

Figure 1: West Branch, km 0+000 - 19+400. Cant deficiency (I), rate of change of cant deficiency $(d I / d t)$ and rate of change of cant $(d D / d t)$ for the transition curves at the proposed speed profile (up to $160 \mathrm{~km} / \mathrm{h}$ ).

In a Swedish project with the same permissible speed in the first phase of operations $(160 \mathrm{~km} / \mathrm{h})$, transition curves for 2000 metres radius are $300 \mathrm{~m}$ long [7]. The longer transition curves result in better comfort values (lower cant deficiency and lower rate of change of cant deficiency), which can be seen in Figure 2.

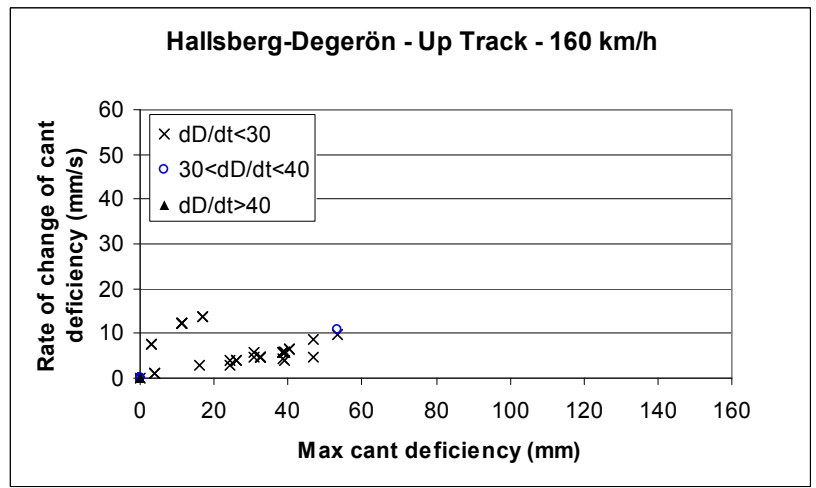

Figure 2: $\quad$ Mixed traffic line Hallsberg - Degerön. Cant deficiency $(I)$, rate of change of cant deficiency $(d I / d t)$ and rate of change of cant $(d D / d t)$ for the transition curves in the up track at $160 \mathrm{~km} / \mathrm{h}$. applied cant according to the $1^{\text {st }}$ phase of operation [7].

Alternatively, the longer transition curves can be used for increasing the permissible speed without exceeding the limits, Figure 3.

The approach to prepare the alignment for a higher speed than the planned operational speed in the $1^{\text {st }}$ phase of operation is not unique for Hallsberg Degerön. Another example is the commuter railway Citybanan in Stockholm, Figures 4 and 5. 


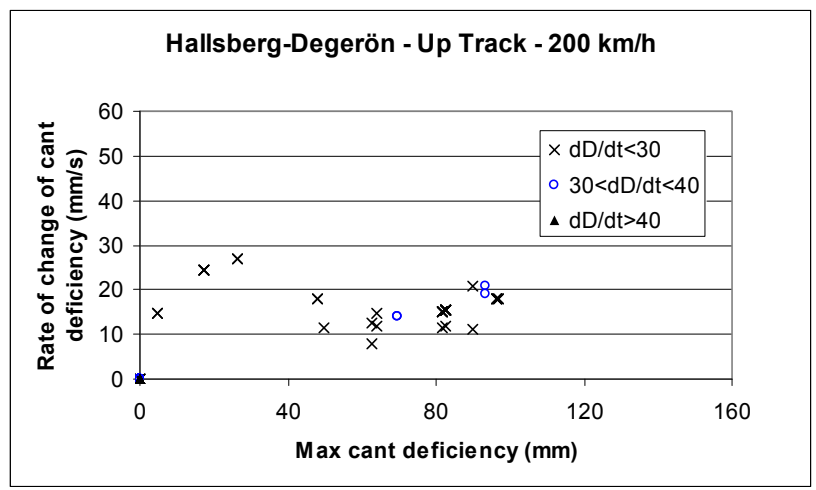

Figure 3: $\quad$ Mixed traffic line Hallsberg - Degerön. Cant deficiency ( $I)$, rate of change of cant deficiency $(d I / d t)$ and rate of change of cant $(d D / d t)$ for the transition curves in the up track at $200 \mathrm{~km} / \mathrm{h}$. increased cant compared to the $1^{\text {st }}$ phase of operation [7].

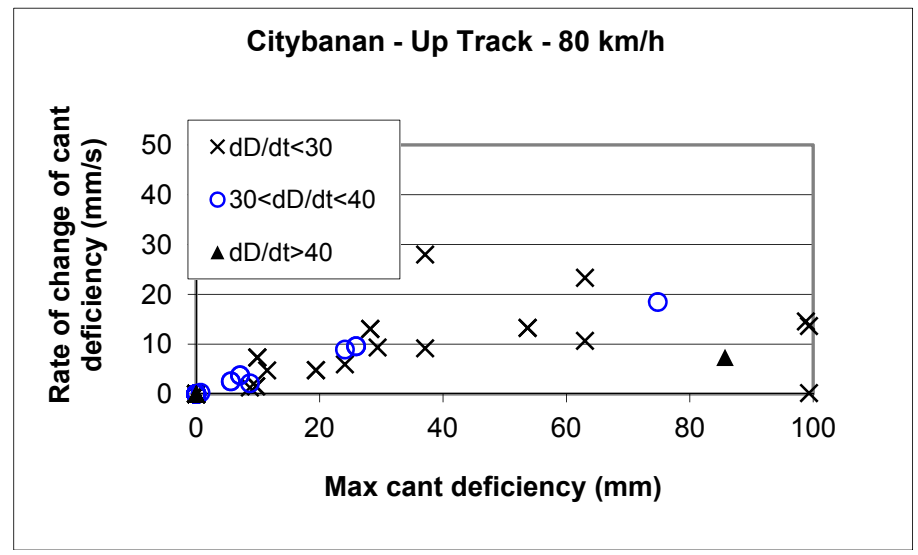

Figure 4: Commuter railway Citybanan in Stockholm. Cant deficiency (I), rate of change of cant deficiency $(d I / d t)$ and rate of change of cant $(d D / d t)$ for the up track and a permissible speed of $80 \mathrm{~km} / \mathrm{h}[6]$.

\subsection{Reverse curves without transition curves}

EN 13803-2 [3] has certain safety-related rules for small radius curves $(R<220$ metres $)$ in the opposite directions. The rules are aimed to prevent buffer locking between two adjacent $26.4 \mathrm{~m}$ long vehicles. Even though certain vehicles (such as multiple units) may have central couplers instead of buffers, there may still be limitations on the possible differences in the end throws between two adjacent vehicles. (Actually, there has been at least one derailment in Sweden where EMUs with central couplers ran on a track where the buffer locking rules in EN 13803-2 were not fulfilled.) 


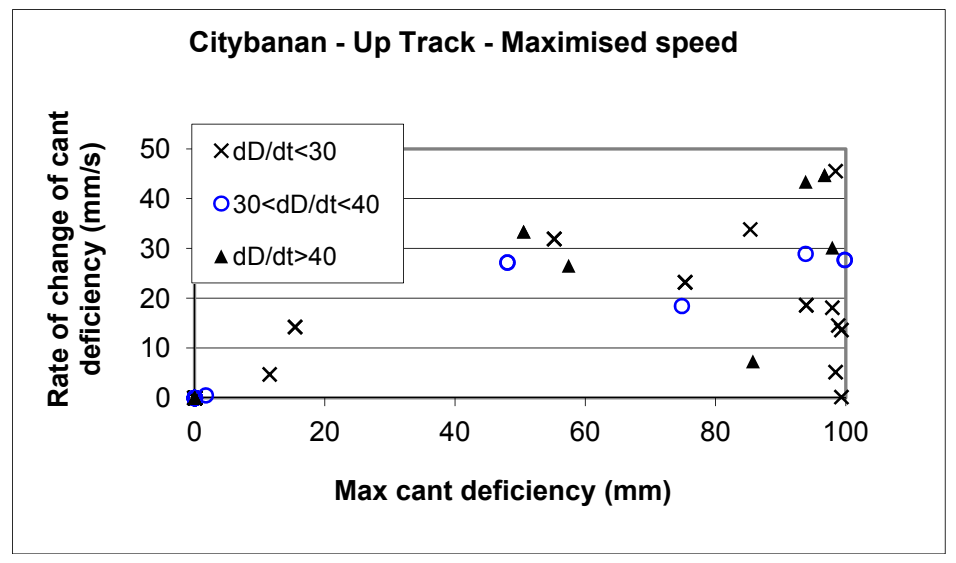

Figure 5: Commuter railway Citybanan in Stockholm. Cant deficiency $(I)$, rate of change of cant deficiency $(d I / d t)$ and rate of change of cant $(d D / d t)$ for the up track and a maximised speed profile (up to $100 \mathrm{~km} / \mathrm{h})[6]$.

On tracks where trains are running with passengers, the buffer locking rules may also be considered as a comfort criterion, since the magnitude and the rate of change of the difference of end throws affect the relative positions of the gangways of the vehicles.

It should be noted that transition curves are preferred and recommended also where they are not necessary according to the requirement in the track standards, since they result in lower peak values for lateral acceleration, lower lateral jerk and lower forces between the wheel and the rail [10].

\subsection{Vertical curves coinciding with transition curves}

Some company standards recommend that vertical curves do not overlap transition curves in the horizontal alignment. Sometimes it is claimed that the recommendation is a comfort criterion, sometimes it is claimed that it aims to enable easy track maintenance.

Since the horizontal alignment is normally calculated before the vertical alignment, this recommendation tends to encourage the designer to use as short transition curves as possible, in order to maximise the freedom in subsequent vertical design. It tends also to encourage the designer to use small vertical radii in order to reduce the length of the vertical curve. The recommendation is therefore in conflict with the design philosophy outlined in Sections 4.4-4.7.

It must be questioned whether or not it is a comfort problem when a transition curve (with or without a cant transition) coincides with a vertical curve. The European Standard for evaluation of ride comfort for passengers, EN 12299 [9], does not take into account any interaction between roll motions and vertical motions or between lateral jerk and vertical motions.

With regard to track maintenance with a tamping machine, is should be noticed that both horizontal and vertical curves require a versine (proportional to 
curvature) to be introduced to the measuring system. For tamping machines without microcomputers, these insertions of versines require manual handling by the machine operator. The changes of horizontal versines take place during passage of the transition curves, and of vertical versines when the tamping machine passes a vertical tangent point (during a length which equals the measuring base of the machine). Hence, if it is at all a problem to handle versines in vertical and horizontal directions simultaneously, the criterion should not be to avoid overlapping between vertical curves and transition curves, but where possible to avoid tangent points in the vertical alignment inside a transition curve.

The claimed problems with vertical curves overlapping transition curves are not believed to be correct (or significant) by many railway companies, and therefore this criterion was not accepted by the client's organisation in this particular project. The claimed problems were not accepted to justify short transition curves and short vertical curves with small radii.

\subsection{Alignments and non-ballasted tracks}

Non-ballasted track (slab track) represents a more modern track system than the ballasted track. The installation is often more costly than for ballasted track, but the need for track maintenance (such as tamping) is less which reduces both maintenance costs and traffic disruptions. The benefit/cost ratio depends on traffic volume, but also whether the track is built at grade, on viaducts or in tunnel.

However, from the alignment point of view, there are certain risks with the slab track. It is much more costly to change the geometry of a slab track, than of a ballasted track. Hence, there is a risk that the track will be locked into a position which may not really suit future operational needs. ("Ballasted track is much more versatile when it comes to redesigning layouts, geometry to meet new strategic requirements as markets and technology evolves. If Britain's railways had been entombed in concrete over the last 40 years or so, it is quite likely they would have died as a result, being unable to adapt efficiently." [11]) See Figure 6 for an example where non-ballasted tracks have resulted in reverse curves with small radii.

\section{Discussion and conclusions}

Railway alignment has a high degree of permanence. Experience shows that railway alignment should be seen in a context of at least 100 years. Installations such as track superstructure, catenary system etc., are less permanent since these subsystems are commonly renewed without alteration of the alignment.

When new lines are built, there are relatively few obstacles along the route, and the available terrain corridor allows a relatively large number of possible alignment alternatives.

In track renewals or upgrading of existing lines and stations, the number of obstacles along the railway is higher, since these include the original obstacles 


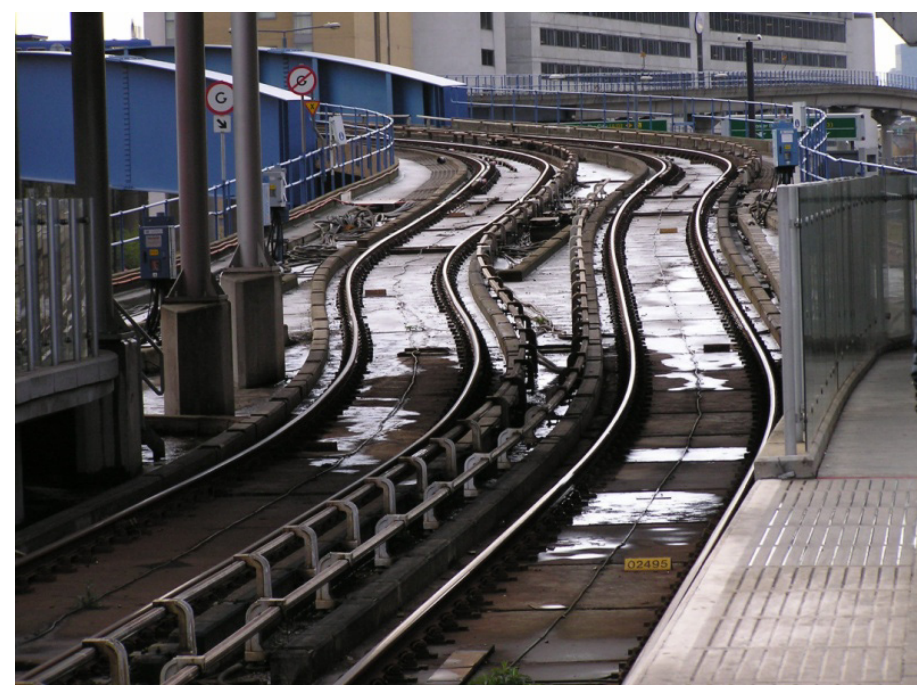

Figure 6: The alignment of Docklands light railways at poplar station, after some re-configurations. Since it is costly to alter the alignment of a non-ballasted track, the re-aligned parts of the tracks appear to have been made as short as possible. (Photo: B Kufver.)

plus the railway-specific installations (such as catenary masts, bridges etc.) along the railway. Therefore, the possibilities of improving an existing alignment are always fewer and more costly compared to improvements during the design of a new railway.

The existing international standards from UIC and CEN should be regarded as standards (specifying limits) and not as design manuals or design handbooks (specifying recommendations). The requirements are formulated as inequalities, which normally gives the alignment engineer intervals for the design values. These intervals should be used for a careful and insightful optimisation of the track alignment, with a special focus on possible changes in the operational requirements, especially when this can be done within the allocated terrain corridor and without increasing the construction cost for the project. These operational requirements may include future turnouts, introduction of skip-stop trains and a general increase in permissible speeds.

The need for an insightful alignment optimisation is especially high where the track will be non-ballasted.

\section{Acknowledgements}

The authors thank Ferroplan Sweden AB and WSP International Sweden AB for permission to publish this paper. 


\section{References}

[1] UIC. Trassierungsmerkmale der von schnellen Reisezügen befahrenen Gleise. UIC 703 OR ( $2^{\text {nd }}$ edition). Paris, 1989.

[2] CEN. Railway applications - Track alignment design parameters - Track gauges $1435 \mathrm{~mm}$ and wider - Part 1: Plain line. ENV 13803-1:2002, European Committee for Standardization, Brussels.

[3] CEN. Railway applications - Track - Track alignment design parameters Track gauges $1435 \mathrm{~mm}$ and wider - Part 2: Switches and crossings and comparable alignment design situations with abrupt changes of curvature. EN 13803-2:2006, European Committee for Standardization, Brussels.

[4] Kufver, B. \& Rydell, O. Certain aspects of the CEN standard for plain line alignments. Proc. of Railway Engineering - 2009, Engineering Technics Press: Edinburgh. ISBN 0-947644-65-2.

[5] CEN. Railway applications - Track - Track alignment design parameters Track gauges $1435 \mathrm{~mm}$ and wider - Part 1: Plain line. EN 13803-1:2010, European Committee for Standardization, Brussels.

[6] Kufver, B. Alignment design for Citybanan in Stockholm. Proc. of Urban Transport 2004, CMP/WIT Press: Southampton, pp.489-497. ISBN 185312-716-7.

[7] Kufver, B. Alignment design for the double tracking Hallsberg - Degerön. Proc. of Railway Engineering - 2011, Engineering Technics Press: Edinburgh. ISBN 0-947644-69-5.

[8] Kufver, B. Optimisation of horizontal alignments for railways - Procedures involving evaluation of dynamic vehicle response. $\mathrm{PhD}$ thesis, TRITA-FKT Report 2000:47, KTH, Stockholm (2000).

[9] CEN. Railway applications - Ride comfort for passengers - Measurement and evaluation. EN 12299:2009, European Committee for Standardization, Brussels.

[10] Kufver, B. \& Förstberg, J. Dynamic vehicle response versus virtual transitions. Proc. of Comprail 2004, CMP/WIT Press: Southampton, pp. 799-807. ISBN 1- 85312-715-9.

[11] Brown, R. Ballastless track. Permanent Way Institution Journal and Report of Proceedings. January 2010. Vol 128, part 1, page 29. 